\title{
Recurrent Liposarcoma
}

National Cancer Institute

\section{Source}

National Cancer Institute. Recurrent Liposarcoma. NCI Thesaurus. Code C8818.

The reemergence of a malignant adipose tissue neoplasm after a period of remission. 